\title{
Mulemba
}

Revista Angolana de Ciências Sociais

5 (10) | 2015

Angola 40 anos de independência: memória, identidades, cidadania e desenvolvimento

\section{Agricultura familiar em Angola: as armadilhas conceituais da classificação dicotómica}

Family farming in Angola: the conceptual traps of dichotomous classification

\section{Garcia Neves Quitari}

\section{(2) OpenEdition}

\section{Journals}

Edição electrónica

URL: http://journals.openedition.org/mulemba/2010

DOI: $10.4000 /$ mulemba.2010

ISSN: 2520-0305

Editora

Edições Pedago

\section{Edição impressa}

Data de publição: 1 novembro 2015

Paginação: 233-260

ISSN: 2182-6471

\section{Refêrencia eletrónica}

Garcia Neves Quitari, «Agricultura familiar em Angola: as armadilhas conceituais da classificação dicotómica», Mulemba [Online], 5 (10) | 2015, posto online no dia 12 outubro 2018, consultado o 26 janeiro 2021. URL: http://journals.openedition.org/mulemba/2010 ; DOI: https://doi.org/10.4000/ mulemba.2010 


\title{
Agricultura familiar em Angola: as armadilhas conceituais da classificação dicotómica*
}

\author{
Garcia Neves Quitari**
}

\begin{abstract}
Resumo: No debate em torno da necessidade de desenvolvimento da agricultura familiar em Angola, tem-se tomado como pressuposto um conjunto de dicotomias auto-explicativas, o que engendra uma falsa transparência do seu conceito, e parte dos argumentos a favor da agricultura familiar tem tentado buscar no passado colonial a prova do seu sucesso para o futuro desenvolvimento económico e social do país. No entanto, se por um lado, estas dicotomias sustentam-se mais por uma espécie de silogismos, por outro lado, o recurso ao passado colonial negligencia a história ao não considerar o facto de que a agricultura familiar na era colonial tinha na sua base a expropriação de terra dos africanos, um sistema de trabalho forçado, monopólio colonial da produção e comércio dos produtos agrícolas, em detrimento dos africanos e da agricultura de subsistência. Contra este raciocínio dicotómico, o objectivo deste trabalho é contribuir para compreensão do actual sentido da agricultura familiar em Angola.
\end{abstract}

Palavras-Chave: Angola, agricultura familiar, campesinato.

A primeira versão deste artigo foi apresentada na Faculdade de Economia da Universidade Agostinho Neto (UAN), em Luanda, no dia 16 de Abril de 2014, no âmbito das actividades da I Trienal UAN Humanidades - I Congresso 2014, «Painel temático III: Economia global, desafios locais, empreendedorismo e desenvolvimento sustentável», uma organização das Faculdades de Direito, Economia, Ciências Sociais e Letras da UAN, Luanda, de 11 a 18 de Abril de 2014. Posteriormente, foi lido e discutido no anfiteatro principal da Faculdade de Ciências Sociais (FCS) da UAN, no dia 31 de Outubro de 2014, «Painel Aberto», por ocasião da realização do Iv Colóquio de Ciências Sociais, subordinado ao tema: Globalização, gestão e dinâmicas de desenvolvimento regional e local. $\mathrm{O}$ autor agradece o apoio, sugestões e críticas feitas por ocasião da sua apresentação e agradece o acolhimento e o apoio da direcção e editoria da revista que viabilizaram a sua publicação.

** Sociólogo, Professor Auxiliar do Departamento de Sociologia (Ds) da Faculdade de Ciências Sociais (FCS) da Universidade Agostinho Neto (UAN). 


\section{Introdução}

No debate em torno da necessidade de desenvolvimento da agricultura familiar em Angola, tem-se tomado como pressuposto um conjunto de dicotomias auto-explicativas e parte dos argumentos a favor da agricultura familiar tem tentado buscar no passado colonial a prova do seu sucesso para o futuro desenvolvimento social e económico do país. Todavia, percebe-se que neste debate a agricultura familiar passou a ser um termo polissémico. Têm contribuído para esta polissemia, as dicotomias tradição x modernidade, urbano x rural, das quais decorrem outras contraposições: comércio rural $\mathrm{x}$ comércio urbano, mulher rural $\mathrm{x}$ mulher urbana, jovem rural $\mathrm{x}$ jovem urbano, etc.

Estas dicotomias constituem-se como categorias clarividentes de compreensão imediata. No entanto, são insuficientes para que numa compreensão conceitual, seja observada toda a crítica já elaborada em volta dos modelos de pensamento dicotómico, em grande parte, por não se reflectirem na realidade social, pelo menos, não na forma estanque como pretende este raciocínio classificador. ${ }^{1}$

No raciocínio dicotómico, a agricultura familiar é facilmente compreendida pela sua contraposição, que é a agricultura empresarial. Pela mesma lógica, pressupõe-se que a agricultura familiar envolve todos os membros da unidade familiar. No nosso caso, nota-se então que a falsa transparência do conceito de agricultura familiar - sugestionado pelos termos que o compõem - acaba, paradoxalmente, por ser um obstáculo ao seu conhecimento. Deste modo, tanto as referidas dicotomias quanto a falsa transparência do termo agricultura familiar apresentam-se como o que denominamos de armadilhas conceituais.

Na nossa visão, as políticas de promoção da agricultura familiar em países subdesenvolvidos seguem mais ou menos tendências comuns, em geral, orientadas pelas instituições de desenvolvimento e organizações financeiras internacionais. Entretanto, a sua configuração e experiência em cada país podem depender de um conjunto de dinâmicas internas, que vão desde o nível de aceitação dos governos destas orientações, o regime de governo, formas de participação

1 Sobre tradição e modernidade ver, por exemplo, Hobsbawm e Terence Ranger (2012). Para o caso de Angola, ver também Neto (2004). 
política, passando pela existência de movimentos sociais engajados na luta pela terra, até aos distintos conhecimentos sobre plantio entre agentes públicos e camponeses, por exemplo.

Por conseguinte, é necessário primeiro considerar que o desenvolvimento da agricultura familiar nos últimos anos tem sido uma iniciativa assumida por muitos governos como políticas públicas para fazer face aos desafios de desenvolvimento social e económico. No entanto, empiricamente, devemos considerar estas iniciativas como realidades sociais minimamente variáveis no espaço de acordo com as condições históricas, ideológicas e materiais da sua elaboração, cabendo-nos questionar, para o nosso caso, o que pretendemos denominar como agricultura familiar. Sob esta perspectiva e contra este raciocínio dicotómico-classificador, o objectivo deste trabalho é contribuir para compreensão do actual sentido da agricultura familiar em Angola. Sem pretender esgotar este tema, desejamos, à luz de uma literatura seleccionada, evidenciar o percurso da elaboração conceitual da agricultura familiar e camponesa. ${ }^{2}$

De facto, no actual contexto de Angola, a agricultura é fortemente marcada, por um lado, pela emergência de empreendimentos agrícolas públicos e privados de variadas dimensões e, por outro lado, por uma agricultura camponesa, cuja produção se destina promordialmente ao consumo doméstico e seu excedente para o mercado. Pese embora a confusão conceitual, restam-nos poucas dúvidas de que a base empírica sobre a qual se quer referir a agricultura familiar em Angola é a agricultura camponesa. ${ }^{3}$ Como veremos mais adiante, aqui cabe a ressalva de que, do ponto de vista do debate conceitual, agricultura camponesa pode não ser stricto sensu igual a agricultura familiar.

Alguns pesquisadores contemporâneos que se dedica(ra)m aos estudos conceituais e metodológicos em torno na definição da agricultura familiar e/ou camponesa têm remetido ao início do século

2 Para este texto, valho-me de algumas notas de uma investigação sobre o Projecto Aldeia Nova - Waku-Kungu, realizado entre 2008 e 2009 na ocasião da dissertação do mestrado. Para actualização de algumas informações, realizou--se uma visita de três dias a este local, em Janeiro de 2014, com o auxílio do estudante do curso de Sociologia da Faculdade de Ciências Sociais (FCS) da Universidade Agostinho Neto (UAN), Almeida Sebastião, a quem expresso minha gratidão pela companhia no trabalho de campo e, sobretudo pela transcrição das entrevistas realizadas na referida empreitada.

3 Por exemplo, outro termo recorrente para este segmento tem sido a «agricultura tradicional». 
xx o debate inaugural sobre estes temas, no qual são evidenciadas as contribuições fundamentais de autores como Boguslaw Galesky, Karl Kautsky, Maurice Godelier, Alexander V. Chayanov, Eric R. Wolf, Henry Mendras, dentre outros, cujas abordagens se debruçaram, de um modo ou de outro, sobre a especificidade, interdependência ou integração económica da agricultura camponesa em relação à economia capitalista. ${ }^{4}$

Vale mencionar que no fim do século xx, este debate foi bastante profícuo, principalmente entre as correntes marxistas versus os chamados populistas, debate dentro do qual o camponês configurava-se como uma categoria analítica do sistema capitalista (SHANIN 1980).

Como refere Neves (1981), parte do que estava em jogo neste clássico debate eram três visões sobre o campesinato. Por um lado, a visão segundo a qual os camponeses estariam sob um processo de subordinação em relação ao capital, sob o risco de proletarização ou de transformação destes em pequena burguesia e, por outro lado, uma visão mais optimista que defendia a ideia de que o camponês resistiria a esta pressão do capital. Por fim, como mostra esta autora, uma terceira visão que defendia a sobrevivência do camponês graças à sua capacidade de articulação de diferentes modos de produção.

Dentre os autores referidos acima, destaca-se Chayanov (1981), que em seu famoso livro, publicado em 1924, intitulado A teoria dos sistemas económicos não-capitalistas, defendeu a existência de outras racionalidades económicas, propondo originalmente a necessidade de se considerar a articulação de diferentes racionalidades económicas como forma de se compreender o que denominou de exploração agrícola familiar camponesa. Para o autor, a economia agrícola camponesa operaria com uma lógica diferente da lógica de produção agrícola capitalista.

Segundo sua análise, na economia não-capitalista não estariam ausentes necessariamente todas as categorias da economia capitalista. 236 O que estaria ausente seria o conjunto das categorias, em seu encadeamento perfeito ${ }^{5}$ no sentido de gerar o lucro. Grosso modo, a questão que se coloca como pano de fundo para os autores que compartilham esta perspectiva é a existência de racionalidades distintas que orientam a economia humana. Neste caso, os camponeses operariam com

4 Ver, por exemplo, Shanin (1980), Neves (1981; 1998).

5 Grifo nosso. 
uma racionalidade na qual estaria ausente o cálculo do lucro, significando o seu trabalho apenas um meio de reprodução social.

Mantendo a sua atenção na distinção entre a exploração agrícola camponesa e a exploração empresarial capitalista, para o autor, a ausência de salários no primeiro tipo de exploração será um dos seus elementos distintivos em relação à exploração agrícola capitalista. Embora possam ocorrer pagamentos em dinheiro por trabalhos realizados no âmbito da produção agrícola camponesa, é necessário, para que se considere como salário, que ocorra a dedução do lucro ou da mais-valia, segundo uma interpretação propriamente marxista. ${ }^{\mathbf{6}}$

Ainda segundo o autor, o valor originado do excedente da produção agrícola camponesa, mesmo nas suas melhores condições de disponibilidade e localização em relação ao mercado, não pode ser comparado nem em quantidade nem em qualidade à renda como a que ocorre na economia capitalista.

Desta forma, a contribuição de Chayanov assinala claramente uma distinção de princípios entre a agricultura camponesa e a agricultura empresarial-capitalista. Um outro estudo mais recente é do Hugues Lamarche (1993), cuja contribuição foi fundamental para separação entre campesinato e agricultura familiar. Na sua análise comparativa, parte do princípio de que independentemente da situação sociopolítica, em todos os países de sistemas económicos capitalistas, a produção agrícola, em maior ou menor escala, repousa sempre sobre a produção familiar. ${ }^{7} \mathrm{O}$ autor sugere que a produção agrícola familiar existe em todo o mundo, mas que esta assume diferenças de escala em cada sociedade.

Destarte, voltando-se para compreensão das formas de funcionamento das unidades de produção agrícola familiar em diferentes contextos, para Lamarche, as diferentes denominações encontradas para este tipo de produção torna a exploração familiar uma noção ambígua. Na sua visão, a noção de exploração familiar nos diferentes contextos é carregada de simbologias, situação que também levaria a uma recorrente confusão conceitual entre a agricultura camponesa e agricultura familiar.

6 Como chama atenção o autor, é necessário conservarmos o salário enquanto categoria específica do sistema capitalista a qual estão associadas outras categorias como renda e juros, etc.

7 No seu estudo, confrontou diferentes formas de produção agrícola familiar de diferentes países, na qual o continente africano esteve representado pela Tunísia. 
Para o autor, toda exploração agrícola camponesa é uma exploração familiar, mas nem toda exploração agrícola familiar é camponesa. Segundo Henry Mendras (apud Lamarche 1993: 16), as sociedades camponesas possuem características que as distinguem da sociedade global e, por conseguinte, sua forma de exploração agrícola também se diferencia das outras formas.

No estudo de Lamarche, a partir do nível de integração no mercado, o autor estabelece uma escala progressiva das explorações agrícolas familiares, na qual o ponto de partida seria o modelo original, sendo o top o modelo ideal que, nos melhores casos, é representado pelo tipo de empreendimento empresarial familiar. Nesta escala, o modelo camponês, poderia ser o modelo original, como foi caso da França, segundo este autor, estágio no qual muitos países ainda poderiam ser encontrados actualmente. ${ }^{\mathbf{8}}$

Compartilhando a ideia de que o modelo camponês seria específico e em princípio apenas produtor de subsistências, Lamarche (op. cit.: 19) afirma que as oportunidades para qualquer exploração familiar atingir o modelo ideal dependeria das capacidades dos agentes destas explorações colocarem em marcha suas estratégias em conformidade com o projecto que a sociedade englobante perspectivou para ela.

Por fim, mas não menos importante, vale ressaltar as contribuições de Amin e Vergopoulos (1977), em A questão agrária e o capitalis$m o$, livro no qual, através de uma leitura intensa das análises de Marx e de outros autores, como Lenine, Kautsky e até mesmo de Chayanov, e apoiando-se incidentemente nestes, demonstram as relações históricas entre o capitalismo e a agricultura numa visão global.

Para o efeito do nosso trabalho, cabe-nos destacar quatro ideias fundamentais desses últimos. A primeira ideia reside certamente na afirmação segundo a qual a agricultura estaria historicamente subordinada ao capital nas diferentes fases de expansão do capitalismo.

A segunda é a ideia do capitalismo enquanto sistema mundial, estabelecido por uma divisão internacional do trabalho e alianças de classes, uma relação com diferenciações e continuidades entre $o$ centro e a periferia. ${ }^{9}$ Esta abordagem, na nossa visão, permite aos

8 Nota-se aqui um reconhecimento tácito de em França a agricultura familiar teria evoluído para o actual modelo de empresas agrícolas a partir das explorações camponesas.

9 Ver também Massiah (1977). 
seus autores a incorporação na análise das mais diferentes formas de exploração do capital sobre a agricultura ao arredor do mundo, sobretudo a partir daquilo que considera ser a terceira fase do desenvolvimento de capitalismo que, por sua vez, coincidiria com a expansão imperialista do século xx. A terceira ideia é representada pela afirmação de que a agricultura camponesa não está fora do sistema capitalista, pelo contrário, ela é uma recriação do capital. Num diálogo mais próximo de Chayanov, salvo as devidas diferenças, os autores referem que o camponês não visa ao lucro e acumulação de capital, mas simplesmente a reprodução social. ${ }^{10}$ A quarta ideia diz respeito ao papel da administração colonial como agente impulsionador no processo de introdução do modo de produção em África, como reflecte o trecho a seguir:

«A administração colonial exerceu, pois, funções económicas e sociais desempenhadas em outros lugares pelas classes dominantes locais. Aqui, ${ }^{11}$ ela organizou, através de meios lucrativos, o confinamento de populações em exíguas reservas [...] assumiu, em outras partes, a sucessão de companhias concessionárias, verdadeiras administrações privadas. Retomou igualmente, pela imposição do dinheiro, o trabalho ou a cultura forçados e a utilização da economia de troca. Quando as alianças de classes foram estabelecidas entre administração colonial $e$ as classes dirigentes locais serviram para reforçar sua intervenção directa» (Amin e Vergapoulos 1977: 37).

\section{Do colonialismo à independência de Angola: campesinato ou agricultura familiar?}

Para o caso de Angola, as preocupações sobre as formas de integração/subordinação dos camponeses à economia capitalista foram reflectidas por alguns autores. Ao que tudo indica, a primeira metade do século xx, momento da expansão imperialista, em que ocorreria a

\footnotetext{
${ }^{10}$ Ao nosso ver, a diferença entre as análises de Chayanov e a, posteriori, de Amin e Vergapoulos, está no facto destes não remeterem a ausência do lucro a uma racionalidade camponesa, mas, como os próprios autores defendem, aos mecanismos de exploração do capital, que transferem a renda e toda mais-valia da economia camponesa para o capitalismo urbano.

11 Em África, grifo nosso.
} 
penetração colonial para o interior de Angola, foi também implicitamente considerada por parte destes autores como período de introdução do modo de produção capitalista nesta colónia. ${ }^{12}$

De qualquer modo, a expansão colonial do século xx em Angola foi analisada por estes autores na óptica de um debate internacional fortemente marcado pelo pensamento marxista. Por exemplo, num artigo publicado em 1980, com o título «Sobre a articulação dos modos de produção em Angola: uma nota metodológica», propondo a teoria do modo de produção como forma de melhor entender a estruturação da sociedade colonial angolana e pós-colonial, Franz--Wilhelm Heimer passa em revista as distintas perspectivas metodológicas que teriam sido utilizadas para estudar a (des)integração da sociedade colonial angolana. Na visão de Heimer, o período colonial conjugou lógicas capitalistas e não-capitalistas, conjugação através da qual se gerava o excedente da produção agrícola e se reproduzia uma mão-de-obra barata.

Outro trabalho interessante é o texto de Elisete Marques Silva, intitulado «Impactos da ocupação colonial nas sociedades rurais do Sul de Angola», no qual analisa os impactos da introdução do modo capitalista de produção nas sociedades indígenas agro-pastoris do Sul de Angola. Cabe-nos ainda aqui mencionar o artigo «O imposto de palhota e a introdução do modo de produção capitalista nas colónias» (1978), de autoria de José Capela, no qual destaca a forma «compulsória» como os africanos foram introduzidos na economia monetária para pagamentos de impostos, recorrendo estes à venda da força de trabalho e/ou da produção agrícola aos colonos. De igual modo, também não faltaram visões que postulavam a resistência camponesa em face dos processos de dominação colonial e capitalistas, visões estas que conferiram aos camponeses um papel político proeminente. ${ }^{\mathbf{1 3}}$

Destarte, seja qual for abordagem, nota-se que o recurso à história 240 colonial não pode prescindir do problema social e político intrínseco à colonização como, por exemplo: o racismo e a exclusão dos indígenas, o trabalho forçado, etc. Ao contrário disso, no actual debate

\footnotetext{
12 Longe desta polêmica, na nossa opinião, poucas dúvidas podem ser levantadas sobre o facto de que a colonização do interior de Angola se expressaria através de um capitalismo do tipo predominantemente agrário até a data da sua independência, cujas consequências no presente não podem ser ignoradas.

13 Ver, por exemplo, Davidson (1977).
} 
sobre agricultura em Angola predominam as visões tecnocráticas e economicistas sobre o período colonial que têm ressaltado apenas os elevados índices de produção e a posição alcançada por Angola colonial no comércio internacional de commodities agrícolas, como o café e o algodão, sobretudo entre as décadas de 1960 e 1970.

Entretanto, estas visões só podem ser plausíveis se esvaziado o conteúdo qualitativo da colonização, uma vez que os elevados índices de produção foram alcançados graças a uma exploração da mão-deobra, ao monopólio do comércio dos produtos agrícolas e a expropriação de terra dos nativos. ${ }^{\mathbf{4}}$

É preciso ter em conta que a participação do sector familiar na agricultura colonial se restringia a um sistema de propriedades agrícolas familiares: fazendas e granjas, etc., ao qual os indígenas estavam vetados, salvo como mão-de-obra barata. O estatuto do indígena que vigorou até a década de 1960, não reconhecia o direito de propriedade aos indígenas, cabendo a estes as reservas de terras para os nativos segundo um sistema de segregação entre cidadão e indígena. ${ }^{15}$ Portanto, é necessário frisar que o sector familiar da agricultura colonial não incluía as sociedades camponesas indígenas como consequência de uma sociedade fortemente estratificada por critérios étnicos-raciais e culturais.

A aposta do governo português para modernização «tardia» da agricultura na Angola colonial foi feita pela opção de constituição de colonatos, levado a cabo pela Junta de Provincial de Povoamento (JPP), política com qual o regime tentou dinamizar a economia agrícola colonial através do envio sistemático e subsidiado de migrantes portugueses para o interior de Angola, o que não significa que estes colonos tenham escapado dos mecanismos de exploração do capital.

A eventual participação das sociedades camponesas nativas resultava, por um lado, da pressão de uma economia cada vez mais monetária que, em detrimento da produção de alimentos para subsistência, lhes impunha o cultivo de monoculturas como actividade principal e, por outro lado, pelo aumento da demanda de mão-de-obra barata. Nesse sentido, é necessário ainda ter em conta que a produção camponesa só poderia ser vendida a preços irrisórios para as companhias

\footnotetext{
14 Ver, por exemplo, Ferreira (1985), Freudenthal (1995) e Silva (2003).

15 Ver Ferreira e Veiga (1957).
} 
agrícolas que detinham o monopólio da comercialização e o controlo de acesso ao mercado.

Deste modo, a expansão das monoculturas, o aumento das demandas por terras e força de trabalho, vão estar na base de conflitos entre colonos e africanos. Como sugere Freudenthal (op, cit.: 266), por exemplo, o cultivo «obrigatório» do algodão foi um dos motivos do levante dos camponeses da Baixa de Cassange contra a Companhia Geral de Algodões de Angola (Cotonang) em Janeiro de 1961, considerado como estopim da luta armada para independência de Angola. ${ }^{\mathbf{1 6}}$ Ademais, é necessário considerar que a colonização do interior de Angola não foi no todo um sucesso quando analisada a implementação de assentamentos rurais para colonos e, por conseguinte, as reservas de terras para os africanos.

Bender (1973), por exemplo, ao examinar o caso do Colonato da Cela, afirma que na política de assentamentos rurais planeados do regime colonial português, por diferentes motivos, os casos de sucesso foram excepção e não a regra. ${ }^{17}$ A construção do Colonato da Cela, como exemplo, incluía a construção de diferentes equipamentos sociais como postos de saúde, sistema de captação e distribuição de água, escolas e estabelecimentos de transformação de produtos agropecuários. ${ }^{\mathbf{1 8}}$ Mas, como sugere o autor, ainda assim tornou-se insustentável para o governo colonial a manutenção de uma política de migração subsidiada, não somente pelas diferenças geoclimáticas, mas também, em boa parte, em função da crise política e económica que Portugal enfrentava fora e dentro da metrópole. ${ }^{19}$ Portanto, buscar a garantia de sucesso da agricultura familiar no passado colonial, sem levar em conta as suas contradições, revela-se como um exercício ideológico que negligencia a história. Para fazer jus à história, é preciso assinalar os traços históricos característicos de cada época.

Se, por um lado, o colonialismo significou o desapossamento da terra e a subordinação do camponês africano aos ditames da administração colonial, por outro lado, na curta experiência socialista pós-independência de Angola, «restituiu-se» a terra aos camponeses

\footnotetext{
16 Ver também Bittencourt (2008).

17 Ver também Bender (2013).

18 Sobre os colonatos em Angola, ver também Costa (2006).

19 Segundo Bender (apud PACHeco 2007), o governo português havia gasto um total de 30 milhões de dólares para construção de quinze aldeamentos que formavam o Colonato da Cela, mas das 8400 famílias previstas entre 1959 e 1964, apenas 1700 teriam sido transferidas de Portugal para o Colonato da Cela.
} 
(sem reforma), através da nacionalização e confisco - engendrada pela Lei $n^{0} 3 / 76$ - mas este período pouco ou quase nada significou em termos de um desenvolvimento agrícola. ${ }^{\mathbf{2 o}}$

Diferente de Moçambique, por exemplo, onde a intervenção do Estado socialista no campo foi mais incisiva, em Angola o início recrudescido da guerra civil imediatamente após a independência, com forte incidência no meio rural, impediu uma acção mais prolongada do novo governo no campo. ${ }^{21}$ Mas ainda assim, no plano político e em virtude de uma determinada interpretação do marxismo, segundo a qual os camponeses teriam fraco desenvolvimento da consciência de classe, estes passaram a ser pensados a partir de uma orientação política de acordo a qual os camponeses deveriam a adoptar a forma cooperativista de produção, como demonstra o trecho abaixo: ${ }^{22}$

«A edificação da sociedade socialista e a criação da sua base material, exigem a transformação da pequena economia camponesa e a sua integração progressiva em grandes unidades colectivas, através da aplicação criadora dos princípios cooperativistas de Lénine à nossa realidade» (MPLA-PT 1980: 39).

Segundo indicava o relatório do MPLA-PT, logo após a independência, houve uma tentativa de reerguer o parque agroindustrial, entre 1977 e 1980, sobretudo a partir das infraestruturas coloniais, com base nos princípios da revolução em curso naquele momento, mas sem êxito.

De acordo com a análise do MPLA-PT, durante o $10^{\circ}$ Congresso Extraordinário, realizado em 1980, a guerra civil, a carência de técnicos nacionais especializados, o êxodo rural e a degradação de infraestrutura como estradas, pontes, etc., contribuiriam para que esses projectos de desenvolvimento da agricultura fossem abandonados. Esta perspectiva não pode deixar de considerar as distintas iniciativas do governo único para dinamização do sector agrícola, como a iniciativa das compras públicas e a mobilização social e política dos camponeses, a cargo da Empresa Nacional de Comercialização e Distribuição

\footnotetext{
${ }^{20}$ Sobre a Lei das Nacionalizações e Confiscos, ver Ferreira (2002).

21 Sobre o caso de Moçambique, ver Correia e Homem (1977) e Geffray (1991).

22 O Estado socialista definiria o modelo de produção agrícola com base em uma subdivisão do sector em empresas mistas (privada e estatal), empresas estatais, cooperativas agrícolas, associações camponesas. Ver MPLA-PT (1980).
} 
de Produtos Agrícolas (ENCODIPA) e União Nacional dos Camponeses Angolanos (UNACA), respectivamente. Mas estas iniciativas não alcançaram abrangência nacional considerável, nem na horizontal nem na vertical, por alguns dos motivos já mencionados acima.

Nossa proposta é que o período entre as décadas de 1980/1990 seja entendido como um hiato em termos de desenvolvimento da agricultura, impondo-nos que a análise da actual situação seja feita tendo como panorama o período a partir de 2002, com o fim da guerra civil. Contudo, parece-nos importante não perder de vista que alguns dos aspectos que caracterizam a agricultura em Angola a partir desta data, resultaram também de processos políticos e económicos iniciados nestas duas décadas (1980/1990), como o fim do regime socialista e as reformas estruturais postas em curso na transição para a economia de mercado.

Nesta ordem de ideias, destaca-se em primeiro lugar, a segunda alteração à Lei Constitucional, feita através da Lei no 23/92 de 16 de Setembro, através da qual se aprofundaram as reformas que visavam a transição do Socialismo para o Estado Democrático de Direito e, em segundo lugar, o Programa de Saneamento Económico e Financeiro (SEF), implementado a partir de 1987, sob o auspício do PNUD e do Banco Mundial, que se consubstanciou num pacote de reformas com vista à liberalização da economia. ${ }^{\mathbf{2 3}}$

Para avaliar os impactos destes processos basta mencionar, por exemplo, que foi a partir da aprovação da Lei $n^{0}$ 23/92 que se (re) introduziu em Angola o princípio da propriedade privada da terra, factor de produção fundamental para qualquer análise sobre o desenvolvimento agrícola. Feita esta análise histórica, ainda que limitada, devemos considerar que a retoma dos projectos de desenvolvimento da agricultura em Angola ocorre num novo contexto global, regional e local.

\section{Agricultura familiar em Angola: em busca de um sentido}

Para o melhor debate, devemos inicialmente considerar o desenvolvimento da agricultura familiar em Angola como uma questão

23 Ver Menezes (2000). 
multifacética, que traz à tona novos e antigos desafios, entendimento sem o qual apenas seria possível ver a agricultura familiar numa perspectiva «desenvolvimentista» na qual não são reflectidos a estrutura agrária e a desigualdade de acesso aos recursos naturais e financeiros.

Não trataremos aqui sobre o acesso desigual a esses recursos, porém, incumbimo-nos, por ora, frisar que nesta visão desenvolvimentista, que também tem ressaltado a incapacidade do pequeno produtor, não se tem posto em causa o facto de que os quatro hectares de terra geralmente concedidos pelos programas públicos terem vindo a verificar-se como uma reduzida parcela de terra que inviabiliza a reprodução social camponesa. Também não trataremos sobre a estrutura fundiária do país.

Ao que parece, por esta transformação desejada, do camponês para agricultor familiar, tudo quanto for produção agrícola de pequena escala passa a ser denominado como agricultura familiar, resultando numa polissemia que se pretende indiscutível. ${ }^{24}$ Todavia, na nossa visão, o entendimento sobre a agricultura familiar em Angola, neste momento, requer a captação e demarcação do seu sentido específico por meio de investimento científico-académico que, escapando da visão tecnocrática difundida pelos mídias, contribua para a sua melhor compreensão enquanto uma iniciativa pública.

Fazendo recurso à noção de obstáculos epistemológicos de Bachelard (1996), do nosso ponto de vista, torna-se necessário inverter o vector do conhecimento: do ideal-real para o sentido contrário: do real-ideal. Devemos analisar a realidade social como ela se apresenta. Este desafio começa não só por uma dissecação da realidade camponesa angolana, mas também por uma análise do actual quadro das políticas de Estadojizado para o desenvolvimento agrícola de Angola.

Mas antes disso, é necessário escapar da nossa tendência ao fechamento do debate académico e contextualizar a problemática agrária angolana nas dinâmicas da região meridional do continente africano, cujo cenário indica, em maior ou menor grau, os caminhos possíveis em termos de tipo de políticas agrárias e agrícolas a (não) desenvolver. Assim como em muitos países desta região, salvo as devidas

24 Para a diversidade da situação da agricultura camponesa ver, por exemplo, CEIC (2013: 128). 
proporções, em Angola a maioria da população rural ainda vive em situação de pobreza e depende da agricultura para sobreviver. ${ }^{25}$

Vale também mencionar que as reformas económicas, a que nos referimos acima, implementadas em Angola nas décadas de 1980/1990 constituiram um pacote de ajustes estruturais a que estiveram sujeitos muitos países subdesenvolvimentos na América Latina, Ásia e África. Como afirmam Moyo e Yeros (2005), sob estas reformas económicas, os países periféricos do sistema capitalista foram encorajados à liberalização da economia através da desregulação da moeda e dos preços, privatização dos serviços públicos e privatização da terra.

No actual contexto regional, ao contrário da separação entre os dilemas do desenvolvimento da agricultura, a problemática da ocupação da terra, do exercício do poder tradicional, expansão do agrobusiness, a segurança alimentar e a pressão do capital internacional sobre os recursos naturais, os casos já muito estudados de países como Zâmbia, Zimbabwe, Kenya, Namíbia, Mali, Senegal e África do Sul, e até mesmo de Moçambique, demonstram que estes dilemas articulam-se academicamente em volta daquilo que se tem denominado como nova questão agrária. ${ }^{\mathbf{2 6}}$

Para Samir Amin (2012), a nova questão agrária é resultado de um desenvolvimento desigual, tendo como característica uma combinação de dimensões construtivas e dimensões destrutivas. A primeira dimensão refere-se à acumulação primitiva e aumento da produtividade, enquanto a segunda diz respeito aos distintos aspectos negativos deste processo, incluindo a redução do trabalho agrícola, a actividade para produção de commodities e a destruição da base ecológica necessária à reprodução social das sociedades camponesas. ${ }^{27}$

No que se refere à agricultura familiar, o autor afirma que assim como nos países desenvolvidos (Global North), a agricultura camponesa nos países subdesenvolvidos (Global South) tende a ser integrado ao mercado capitalista também pela via dos programas de 246 agricultura familiar. ${ }^{\mathbf{2 8}}$ No entanto, segundo a sua visão, nos países

$\mathbf{2 5}$ Actualmente, quase 38\% da população do país vive nas áreas rurais, representando 58,3\% da população abaixo da linha da pobreza (INE 2014; MINPLAN 2010).

26 Sobre a relação entre o exercício do poder tradicional e a questão da terra na África do Sul ver, por exemplo, Ntsebeza (2005).

27 Ver também Helliker e Murisa (2011).

28 Grifo nosso. 
desenvolvidos a agricultura familiar apresenta níveis muito altos de produtividade, eficiência de gestão e maior resiliência às variações do mercado e contam com vantagens competitivas asseguradas pelas medidas protecionistas dos seus governos.

Por outro lado, como também analisa o autor, a expansão do capital financeiro nos países pobres tem vindo associado com a destruição da agricultura camponesa, deterioração do sistema alimentar, assim como a exclusão do mercado de milhões de camponeses. É necessário frisar que o acesso à categoria de agricultor familiar nos países subdesenvolvidos ocorre através de processos selectivos, o que nos leva a crer que nem todo camponês virá a constituir-se num agricultor familiar nos termos conferidos pelas iniciativas públicas que visam esta transformação. Para isso, basta pensarmos que nem todo camponês dispõe das condições exigidas para o acesso ao crédito financeiro.

No caso específico de Angola, a agricultura vem se constituindo como um sector relevante nas políticas de desenvolvimento económico e social, sobretudo a partir de 2002. Como prova disso, no Plano Nacional de Desenvolvimento 2013/2017 (PND) - no qual foram definidas as políticas e medidas para o desenvolvimento de médio prazo dos sectores económicos, sociais e de infraestrutura - a agricultura constitui prioridade ao lado de sectores como o da indústria, transportes e energias e águas. No plano em causa, o sector da agricultura está subdividido em 11 subprogramas, dentre os quais destacamos o Programa de Promoção da Agricultura Comercial e o Programa de Desenvolvimento da Agricultura Familiar orientada para o mercado. ${ }^{29}$

Por conseguinte, a reconstrução de alguns pólos agroindustriais herdados do período colonial, como o Pólo Agroindustrial da Cela, e a construção de novos outros, têm sido parte da empreitada para o desenvolvimento da agricultura comercial. ${ }^{30}$ Com estes investimentos no sector, assiste-se em Angola ao surgimento de grandes

29 Dentre outros programas sectoriais do PND, devem ainda ser destacamos para o efeito deste trabalho os seguintes: Programa de Gestão Sustentável dos Recursos Naturais, Programa de Fomento da Actividade Produtiva, Programa de Promoção do Comércio Rural, Programa de Aquisição de Produtos Agroalimentares e a Estratégia Nacional de Segurança Alimentar e Nutricional.

30 O Plano Nacional de Desenvolvimento (PND) define ainda zonas de especializações produtivas, a partir das potencialidades locais e infraestruturas desenvolvidas ao longo do período colonial, a exemplo do café e algodão, tradicionalmente cultivados nas províncias do Uíje e de Malanje, respectivamente. 
empreendimentos agroindustriais como o projecto da Sociedade de Estudos e Desenvolvimento Industrial, Agrícola e Comercial (SEDIAC) e Sociedade Agrícola, Comercial e Industrial, s.A. (Agrowako), ambos na Província do Cuanza Sul e Sociedade de Desenvolvimento do Pólo Agroindustrial de Capanda (sODEPAC), assim como os projectos Biocom - Companhia de Bioenergia de Angola, Gesterra - Gestão de Terras Aráveis, s. A., estes na Província de Malanje. ${ }^{\mathbf{3 1}}$

Desta forma, as linhas de financiamento a cargo do Banco de Desenvolvimento de Angola (BDA), que se operacionalizam através de bancos comerciais, têm sido destinados à agricultura por duas vias: crédito agrícola de campanha e crédito de fomento. $O$ primeiro é destinado aos camponeses e definido previamente para a aquisição de sementes, fertilizantes, instrumentos de trabalho, etc., enquanto que o segundo tem sido destinado para instalação, expansão ou requalificação de projectos agrícolas de média e grandes dimensões.

Assim, nota-se que parte dos investimentos públicos para agricultura têm sido direccionados para a promoção da agricultura familiar por via dos créditos agrícolas de campanha, enquanto que outra parte tem sido voltada para promoção do empresariado nacional através de programas de créditos específicos, ao exemplo do Angola Investe, cujo crédito se destina à micro, pequenas e médias empresas.

Por esta forma, também, à semelhança de muitos outros países da região, os investimentos públicos na agricultura tem sido orientado, segundo uma divisão entre grandes, médios e pequenos agricultores, divisão esta estabelecida através da Lei de Bases do Desenvolvimento Agrário. ${ }^{32}$

No âmbito dos investimentos para promoção da agricultura familiar, os camponeses têm sido incentivados ao associativismo e encorajados à aquisição de crédito e comercialização da produção, filiações a partir das quais passam a ser categorizados como agricultores familiares orientados para o mercado.

Desta forma, o estudo sobre a realidade dos projectos e programas que visam a constituição da agricultura familiar em Angola permite a compreensão das suas contradições, seus aspectos positivos e as

\footnotetext{
${ }^{31}$ Importa salientar que a recuperação do sector agrícola comercial conta com a participação de investimentos privados na modalidade de join-venture. Além da participação de empresários nacionais, empresas públicas têm participado na constituição do capital destas sociedades.

$3^{2}$ Ver Lei n. ${ }^{\circ}$ 15/o5 de 7 de Dezembro.
} 
dificuldades de implementação dos programas exógenos à realidade social. O caso do Projecto Aldeia Nova sobre qual falaremos brevemente serve como um bom exemplo.

\section{O Projecto Aldeia Nova: do real ao ideal}

O Projecto Aldeia Nova (PAN) é um Projecto originalmente de caráter público-privado, financiado pelo Banco Mundial e a União Europeia e desenvolvido através de uma cooperação entre Angola e Israel. Erguido sobre a infraestrutura colonial do antigo Colonato da Cela, o PAN foi criado em 2003, através da Resolução n. ${ }^{\circ}$ 38/o3 do Conselho de Ministros, com vista a beneficiar ex-militares oriundos da União Nacional para a Independência Total de Angola (UNITA) e Movimento Popular de Libertação de Angola (MPLA), desmobilizados ao longo da década de 1990, como demostra o trecho abaixo: ${ }^{33}$

«De acordo com esta resolução $n^{\circ} 38 / 03$, os objectivos dos aldeamentos seriam: reassentamento da população, reintegração de desmobilizados e deslocados de guerra, reabilitação do sector agrário, construção de indústrias agrárias, fornecimento de produtos agrícolas aos mercados locais e para exportação, mais oportunidades de emprego, desenvolvimento económico e social e melhoramento da qualidade de vida». ${ }^{34}$

No PAN, a maioria dos beneficiados em 2009 era composta de exmilitares desmobilizados do MPLA e da UNITA, contemplados com uma residência e uma parcela de terra entre 3 a 4 hectares. Além da plantação de milho, cada residência foi contemplada com um estábulo ou aviário. Desta forma, as famílias beneficiadas eram criadoras de vacas leiteiras ou de galinhas poedeiras, compondo estas uma cadeia produtiva de leite, frango, ovos e seus derivados.

Ao serem contemplados no Projecto, as famílias começaram a vida produtiva com um endividamento inicial, uma vez que as casas e os insumos, assim como os animais lhes foram dados a título de

33 Como já referimos, o Projecto Aldeia Nova foi estudado por mim para dissertação do mestrado entre 2008 e 2009 e revisitado em 2014 para actualização de dados.

34 Diário da República, i série, n. ${ }^{\circ}$ 9, de 16 de Dezembro de 2003. 
empréstimos financeiros. Sobre o rendimento dos beneficiários, deveriam ser debitados mensalmente parte dos valores correspondente ao crédito, enquanto as residências deveriam ser reembolsadas no período de vinte anos, embora até 2009 esta cobrança ainda não tivera iniciado. Tendo sido reconstruídas e ampliadas as infraestruturas do antigo Colonato da Cela, o Projecto Aldeia Nova em toda sua extensão possuía, até aquele momento, uma unidade fabril, estação de captação de água, escolas, centros médicos etc.

Entre 2007 e 2008, as famílias começaram a ser assentadas. No entanto, como uma pequena parte das residências estava habitada sazonalmente desde a independência, e de modo mais permanente a partir de 2002, estas famílias mais antigas foram removidas durante as obras e reassentadas no mesmo período com os ex-militares.

Sendo assim, habitavam nas residências do PAN, população de origem local e ex-militares desmobilizados, dentre os quais, alguns originários do município da Gabela e de outras províncias.

A coordenação do PAN exercia o papel de intermediário entre as famílias e a unidade produtiva na qual são produzidos leites, ovos e derivados com a marca Aldeia Nova. Cabia à coordenação do PAN, o cálculo sobre o valor arrecadado de cada beneficiário, o débito de uma parte para amortização da dívida e o depósito bancário do restante destinado às famílias. Além de intermediário económico, a coordenação também exercia o controlo moral nas aldeias, inclusive, intermediando conflitos locais e entre estes e agentes externos, a exemplo do que ocorria com os conflitos de terra. ${ }^{35}$

Sob forma de cooperativa, os beneficiados recebiam da coordenação do PAN os insumos, tais como milho, ração, adubos e assistência técnica. Por sua vez, os benificiários entregavam a colheita de milho e produção diária de ovos e leites. As famílias bem-sucedidas na gestão da sua vinculação produtiva, cujos chefes não raramente também eram pequenos funcionários públicos locais, exercendo dupla jornada de trabalho, representavam para a coordenação do PAN a prova dos bons resultados. Por outro lado, os benificiários mal-sucedidos mantinham-se no PAN com acumulação de perdas sucessivas na produção e endividamentos prolongados. Nesses casos, era comum que os chefes de família fossem ex-militares desmobilizados e, em alguns casos, deficientes físicos de guerra.

35 Sobre os conflitos de terra no Waku-Kungu, ver Quitari (2011). 
Na visão da coordenação do PAN, os beneficiários mal-sucedidos eram preguiçosos, poucos dedicados ao trabalho e acostumados a uma relação paternalista com o Estado. No entanto, estas diferentes visões informam sentidos distintos sobre o Projecto, porque na visão destes beneficiários, o endividamento e, sobretudo a cobrança dos bancos, constituíam um insulto moral, uma vez que na qualidade de ex-militares, viam-se no direito a todo apoio necessário para reorganização das suas vidas.

Para estes, não fazia sentido que um Projecto do Estado daquela natureza fosse insensível à sua condição de ex-militares. ${ }^{36}$ Esses questionamentos, ainda que feitos com base na esperança de que o Estado intercederia juntos aos bancos, tentavam verbalizar formas de resiliência em relação à orientação e funcionamento do Projecto, $\mathrm{o}$ que poderia significar que muitos desses agricultores teriam preferido não participar do circuito de produção do PAN. ${ }^{37}$

Esta situação até 2009 se agravava pelo facto da assistência técnica ter vindo a ser feita por técnicos israelitas, que quase nem a língua portuguesa dominavam, necessitando em alguns casos de tradutores. O domínio de diferentes técnicas de cultivo, a necessidade de uma vigilância sistemática dos aviários e estábulos, o controlo das condições climáticas, assim como toda gestão financeira das unidades residenciais e produtivas demandavam da parte dos beneficiários a incorporação de novos conhecimentos sem os quais as oportunidades de fracasso mostravam-se maiores.

Faz-se necessário referir que no caso da vinculação ao Projecto, a produção a ser entregue à unidade fabril do PAN, a exemplo do milho, devia obedecer a uma qualidade do produto estipulada pela coordenação fora da qual esses produtos eram pagos a preços inferiores ou rejeitados, restando nesses casos, a venda no mercado paralelo da cidade.

Ao contrário dos casos de sucesso, em que a contratação de mãode-obra extrafamiliar era mais frequente, sobretudo nos períodos de plantio e colheita, a situação mais precária era representada por famílias nucleares cujos chefes foram ex-militares, sem possibilidades de contratação de mão-de-obra externa. Pelo controlo moral exercido pela coordenação do PAN aos ex-militares, foi vetada a possibilidade

${ }^{36}$ Ao contrário das formas valorizadas de conflitos sociais, o caso dos ex-militares do PAN poderia ser analisado na perspectiva da luta por reconhecimento. Sobre esta perspectiva, ver Honneth (2003).

${ }^{37}$ Para este trabalho, adopto a noção de resiliência utilizada por Milando (2013). 
de coabitação com mais de uma esposa. Cada residência devia alojar somente uma esposa, o que, em alguns casos, significava a presença da segunda esposa fora das residências do PAN.

Os filhos e agregados (sobrinhos, cunhado[a], netos etc) adolescentes nem sempre participavam das actividades agrícolas, ocupando-se estes das tarefas do cuidado domésticos nos períodos anteriores e posteriores à escola. No caso dos jovens formados, inclusive pelo Instituto Médio Agrário da Cela, observava-se a busca de vinculação à unidade fabril do PAN e, não raros casos, a migração destes jovens para as províncias do Huambo e Benguela, e até mesmo Luanda, onde buscavam por outras oportunidades de trabalho.

Até aqui, nota-se que pelo detalhamento do caso do PAN, os estudos de campo naquela altura permitiram-nos perceber também as alterações culturais resultantes directamente da implementação deste projecto. Primeiro, a necessidade de sucesso da unidade de produção doméstica para manutenção no circuito comercial do Projecto, impunha maior dedicação da família nuclear em detrimento da forma comunitária da lavoura ou da ajuda mútua culturalmente predominante nas zonas rurais. Segundo, a limitada extensão de terra impedia a reprodução social camponesa, na medida em que não havendo terra para dividir, os filhos e agregados emancipados deveriam buscar outras formas de sobrevivência fora do PAN.

Estudos de casos como estes são importantes também porque, por um lado, permitem centrar a análise sobre a capacidade da força produtiva das famílias, uma vez que o pressuposto geral e imediatamente assumido é de que a agricultura familiar, no caso de Angola, integra todos os membros da unidade familiar e, por outro lado, possibilitam demonstrar como a intervenções das políticas estatais podem impactar sobre as formas de organização da vida comunitária, neste caso particular, incidindo sobre a organização do trabalho e na estrutura da família extensa que ainda caracteriza as sociedades camponesas em Angola.

\section{Considerações finais}

O conjunto de iniciativas para o desenvolvimento da agricultura em Angola vem-se configurando por uma opção de mercado e com forte estímulo para a presença do capital na agricultura, pese embora o carácter selectivo de parceiros e o seu relativo fechamento em relação 
à pressão do capital financeiro internacional, particularmente interessado no agrobusiness, que actualmente afecta o continente africano.

Mesmo assim, além da pressão sobre a terra arável e outros recursos naturais, os danos ambientais pelo uso intenso de agrotóxicos, é necessário ressaltar que a especialização produtiva e a produção de commodities agrícola aos quais está vocacionada esta grande agricultura, pode ser incapaz de combater a fome salvo uma inversão contra as forças do mercado. Em geral, a produção de commodities responde antes a uma demanda do mercado internacional, muitas vezes, sobrepondo-se à vontade política.

No nosso caso, os tipos e os destinos da produção agrícola continuarão a ser fundamentais no que se refere à necessária convergência destes dois aspectos com a base alimentar e o consumo interno. Nesse sentido, a aposta no modelo de agricultura familiar constitui actualmente uma questão de soberania alimentar, sobretudo quando adoptados com respeito ao princípio da autonomia, em termos da escolha do tipo de produção e a diversidade da produção de acordo com a base alimentar local.

Nesse sentido, a orientação da agricultura familiar para o mercado pode contriar a soberania alimentar, salvo se prescindir do carácter impositivo da produção agrícola familiar especializada, o que geralmente resulta numa utilização dos espaços intersticiais da lavoura para plantação de alimentos para o consumo familiar. A ameaça à soberania alimentar consiste na inversão da produção agrícola para o mercado e o excedente para o consumo.

De realçar que as iniciativas de compras públicas e os créditos agrícolas, muito bem-vindos para a agricultura familiar, constituemse como mecanismos de mercado, que podem exercer certa pressão sobre os agricultores, sobretudo quando considerados, dentre outros, as altas taxas de juros, a ausência de seguros agrícola e, por conseguinte, impôr maior dedicação destes para o mercado em detrimento da produção de alimentos para o consumo doméstico.

Ademais, a agricultura familiar nos termos que se sugere, deve ser entendido como conceito político e operacional, cuja finalidade é o enquadramento institucional, através das políticas públicas agrícolas das famílias camponesas ao mercado. ${ }^{38}$ De modo mais amplo, a

${ }^{38}$ Para esta perspectiva, valho-me das contribuições de Neves (2005) para o caso do Brasil, no que se refere ao enquadramento social dos camponeses às políticas de fortalecimento da agricultura familiar. 
promoção da agricultura familiar e as medidas de políticas de combate à pobreza, a estratégia nacional de segurança alimentar, assim como a promoção da mulher rural, devem ser vistas como parte de um quadro consubstanciado pelo conjunto de «novas» intervenções estatais no meio rural no período pós-guerra civil.

Assim sendo, a compreensão da agricultura familiar passa também pelo entendimento do modelo de intervenção do Estado nesta re-significação da agricultura camponesa, o que significa o entendimento das formas de categorização dos agricultores, a sua filosofia e critérios e, sobretudo, pelo entendimento dos processos administrativos que operam a transformação de camponeses a agricultores familiares. Faz-se necessário avançar para a definição de um quadro de políticas públicas e não de iniciativas valorativas e transitórias e, deste ponto de vista, das políticas públicas, considerar que são vários os factores culturais, políticos e técnicos que podem determinar o (in) sucesso dos resultados.

Como tentamos brevemente demonstrar, o caso do PAN permitenos aferir que as políticas públicas podem ser portadoras de virtudes técnicas, mas sobre as quais deve-se incorporar outras dimensões da vida. É necessário pensar num tipo de intervenção social que ultrapasse a perspectiva técnica, que incorpore formas de mediação social e, sobretudo, privilegiar a integração social da população rural mais pela via da cidadania, do reforço e combinação com a cultura local, do que pela via do mercado, que tende à despersonalização. De qualquer forma, entendemos que tanto os diferentes conhecimentos técnicos quanto as diferentes visões de mundo e as experiências culturais podem impôr-se como obstáculos à implementação das iniciativas de políticas públicas.

Basta uma breve observação, para percebermos que o campo semântico é capaz responder pelo maior número fracassos das iniciativas públicas, que em geral envolvem grupos sociais com conhecimentos técnicos e culturais diferentes. Um exemplo mais geral sobre esta interseção cultural pode ser percebido num estudo sobre a implementação da Linha Especial de Crédito Agrícola de Campanha, realizado pela Acção para o Desenvolvimento Rural de Angola (ADRA) em 2014, em que diferentes visões sobre o modo de funcionamento do crédito parece terem sido mais importantes do que os condicionamentos naturais para os resultados da referida iniciativa.

Ocorre, por exemplo, que o desconhecimento do ciclo agrícola de variados produtos e os aspectos culturais envolventes no ciclo produ- 
tivo por parte dos operadores de crédito resultam em constrangimentos no funcionamento dos programas de financiamento da pequena agricultura. Nunca é demais referir, que para o camponês, não basta que lhe seja concedido o crédito mas, fundamentalmente, que este crédito seja disponibilizado em tempo oportuno de acordo com o ciclo de produção agrícola.

Por outro lado, na nossa visão, a implementação de modelos de políticas públicas agrícolas devem ser acompanhados de estudos consequentes, sem prejuízo das opiniões diversas que têm dominado o debate. Desta forma, a contribuição académica desejada insere-se no sentido de uma crítica construtiva, devendo para o efeito estudar os diferentes casos, cujos resultados podem, do ponto de vista da operacionalização das políticas públicas, subsidiar a decisão política. Ainda no nível da gestão pública, a opção em relação aos modelos de desenvolvimento postos em marcha ou ventilados para o futuro devem ser comparados com as suas consequências positivas e negativas irremediáveis, tendo em conta as distintas experiências regionais e internacionais.

\section{Referências bibliográficas}

ACÇÃO PARA O DESENVOLVIMENTO RURAL E AMBIENTE (ADRA)

2014, Estudo sobre a implementação da linha especial de crédito agrícola de campanha. Relatório. Luanda, ADRA - Unidade de Lóbi e Advogacia Social, 6op.

AMIN Samir

2012, "Contemporary imperialism and the agrarian question», in Agrarian South: Journal of Political Economy, n. ${ }^{\circ}$ 1, pp. 11-26.

Amin Samir e Vergopoulos Kostas

1977 (2. ${ }^{\mathrm{a}}$ edição), A questão agrária e o capitalismo. Tradução de Beatriz Resende. Rio de Janeiro, Paz e Terra.

BACHELARD Gaston

1996, A formação do espírito científico: contribuição para uma psicanálise do conhecimento. Tradução de Estela dos Santos Abreu. Rio de Janeiro, Contraponto.

BENDER Gerald J.

2013 (3. ${ }^{a}$ edição), Angola sob o domínio português. Mito e realidade. Luanda, Mayamba Editora.

1973, «Planned rural settlements in Angola, 1900-1968» in Franz--Wilhelm Heimer (ed.), Social change in Angola. München, Welt 
forum Verlag for the Arnold-Bergstraesser-Institute [ «Materialien zu Entwicklung un Politik»; 4], pp. 235-279.

\section{BitTENCOURT Marcelo}

2008, «Estamos juntos!»O MPLA e a luta anticolonial (19611974). Prefácio de David Birmingham, volume I. Luanda, Editorial Kilombelombe [«Ciências Humanas e Sociais: Série História de Angola»; 3].

CAPELA José

1978, O imposto de palhota e a introdução do modo de produção capitalista nas colónias. As ideias coloniais de Marcelo Caetano: legislação do trabalho nas colónias nos anos 60. Porto, Afrontamento [«As armas e os varões»; 6].

CENTRO DE ESTUDOS E INVESTIGAÇÃO CIENTÍFICA (CEIC)

2013, Relatório económico de Angola. Luanda, Universidade Católica de Angola - CEIC.

Chayanov Alexander

1981, «Sobre a teoria dos sistemas econômicos não capitalistas», in José Graziano da Silva e Verena Stolcke (orgs.), A questão agrária. São Paulo, Brasiliense, pp. 134-163.

CORreia Sônia e Homem Eduardo

1977, Moçambique: primeiras machambas. Rio de Janeiro, Margem Editora.

Costa Elisa Lopes Ferreira da 2006, Os colonatos em Angola: génese, evolução e seu estado actual. Tese de doutoramento. Universidade Técnica de Lisboa.

DAVIDSON Basil

1977 (2. ${ }^{\mathrm{a}}$ edição), Os camponeses africanos e a revolução. Tradução de António Neves-Pedro. Lisboa, Livraria Sá Costa Editora [«Cadernos livres»; 4].

FERREIRA Eduardo de Sousa

1985, «A lógica da consolidação da economia de mercado em Angola, 1930-70», Análise Social (Lisboa), vol. xxI, n. ${ }^{\circ} 85^{-1} .^{\circ}$, pp. 83-110.

256 FERrEIRA Manuel Ennes

2002, «Nacionalização e confisco do capital português na indústria transformadora de Angola (1975-1990)», Análise Social (Lisboa), vol. XXXviı, n. ${ }^{\circ}$ 162, pp. 47-90.

Ferreira José Carlos Ney e Veiga Vasco Soares da

1957 (2. ${ }^{a}$ edição), Estatuto dos Indígenas Portugueses das Províncias da Guiné, Angola e Moçambique (Anotado e legislação complementar). Lisboa, Edição dos Autores. 
FrEUDENTHAL Aida

1995/1999, "A Baixa de Cassanje: algodão e revolta», Revista Internacional de Estudos Africanos (Lisboa), n. ${ }^{\circ}$ 18-22, pp. 245-283 .

GEFFRAY Christian

1991, A causa das armas: Antropologia da guerra contemporânea em Moçambique. Tradução Adelaide Odete Ferreira. Porto, Afrontamento [«Textos»; 20].

HeIMER Franz-Wilhelm

1983, «Sobre a articulação dos modos de produção em Angola.

Uma nota metodológica», Análise Social, vol. xIX, n.os 77-78-79 $\left(3 .^{\circ}-4 \cdot^{0}-5{ }^{0}\right)$, pp. 1091-1100.

HELLIKER Kirk e Murisa Tendai (eds.)

2011, Land struggles and civil society in Southern Africa. New Jersey, Africa World Press.

Hobsbawm Eric e Ranger Terence

2012 (2. ${ }^{\mathrm{a}}$ edição), A invenção das tradições. Tradução de Celina Cardim Cavalcante. Rio de Janeiro. Editora Paz e Terra.

HonNeTh Axel

2003, Luta por reconhecimento: a gramática moral dos conflitos sociais. Tradução de Luiz Repa. São Paulo, Editora 34.

INSTITUTO NACIONAL DE ESTATÍSTICA (INE)

2014, Resultados preliminares do Recenseamento Geral da População e Habitação. Luanda, INE. Disponível em <www.ine.gov.ao>

KAUTSKY Karl

1980, A questão agrária. Tradução de C. Iperoig. São Paulo, Proposta Editorial.

LAMARCHE Hugues

1993, Agricultura familiar. Comparação internacional, uma realidade multiforme. Tradução de Ângela Maria Naoko Tijiwa. São Paulo, Editora da Universidade Estadual de Campinas.

LÊNIN Vladimir Ilitch

1980, O programa agrário da social-democracia na Primeira Revolução Russa de 1905-1907. Tradução de E. Huggins. São Paulo, Ciências Humanas.

1985, O desenvolvimento do capitalismo na Rússia. Tradução de Adail Sobral e Maria Stela Gonçalves. São Paulo, Nova Cultural.

Massiah Gustave

1997, «Divisão internacional e alianças de classes», in Samir Amin (coord.), A crise do imperialismo. Tradução Marcos Arão Reis. Rio de Janeiro, Edições Graal, pp. 93-164. 
Menezes Solival

2000, Mamma Angola: Sociedade e economia de um país nascente. São Paulo. EDUSP - Editora da Universidade de São Paulo e FAPESP.

Milando João

2013, Desenvolvimento e resiliência social em África. Dinâmicas rurais de Cabinda-Angola. Luanda. Mayamba Editora e Imprensa Nacional de Angola.

MINISTÉRIO DO PLANEAMENTO

2010, Relatório sobre os objectivos do desenvolvimento do milénio. Luanda, Ministério do Planeamento. Disponível em <http:// www.undp.org>

MINISTÉRIO DO PLANEAMENTO E DESENVOLVIMENTO TERRITORIAL

2012, Plano Nacional de Desenvolvimento 2013-2017. Ministério do Planeamento e do Desenvolvimento Territorial, Dezembro.

Moyo Sam e Yeros Paris 2005, Reclaiming the land. The resurgence of rural movements in Africa, Asia and Latin America. Londres, New York, Cape Town, Zed Books.

MPLA - PARTIDO DO TRABALHO

1980, Orientações fundamentais para o desenvolvimento económico-social da Repúlica Popular de Angola, período de 1981-1985. I Congresso Extraordinário do MPLA - Partido do Trabalho, 17-23, Dezembro 1980. Luanda, Edição do Secretariado do Comité Central; Imprensa Nacional - U.E.E., 204p.

Neto Maria da Conceição

2004, «Respeitar o passado e não regressar ao passado», in $\mathrm{Ku}$ longa. Revista de Ciências da Educação e Estudos Multidisciplinares (Luanda), Edições Kulonga, n. ${ }^{\circ}$ 3, pp. 49-69; ver igualmente em $1 .^{\circ}$ Encontro Nacional sobre a Autoridade Tradicional em Angola, Luanda, 20-22 de Março de 2002. Luanda, Ministério da Administração do Território, pp. 177-194.

Neves Delma Pessanha

2005, «Campesinato e reenquadramentos sociais: os agricultores familiares em causa», Revista NERA (Presidente Prudente), Ano 8, n. ${ }^{\circ}$ 7, Julho/Dezembro, pp. 68-93.

1981, Lavradores e pequenos produtores de cana. Estudo das formas de subordinação dos produtores agrícolas ao capital. Rio de Janeiro, Zahar Editores.

1998, «O econômico e o familiar: interdependências, potencialidades e constrangimentos», in D. M. Mota et al. (eds.), Agricultura familiar: desafios para a sustentabilidade (Coletânea). Aracaju, EMBRAPA-CPATC, SDR/MA, pp. 13-33. 
NTSEBEZA Lungisile

2005, Democracy compromised. Chiefs and the politics of the Land in South Africa. Leiden, Brill.

Pacheco Fernando

2007, Procurando um modelo de desenvolvimento para Angola: o caso do Wako Kungo. Luanda, CEAST - Conferência Episcopal de Angola e São Tomé/Centro Cultural Mosaiko.

QUITARI Garcia Neves

2011, «O problema da terra. O Estado e a distribuição de direitos à terra - o caso do Waku Kungo", Mulemba - Revista Angolana de Ciências Sociais (Luanda), vol. I, n. ${ }^{\circ}$ 2, Outubro, pp. 29-48.

REPÚBLICA DE ANGOLA

2005, «Lei de Bases do Desenvolvimento Agrário», in Diário da República (Luanda), Lei n. ${ }^{\circ}$ 15/o5 de 7 de Dezembro.

2003, "Resolução n. ${ }^{0} 38$ do Conselho de Ministros», Diário da República (Luanda), i série, n. ${ }^{\circ}$ 9, de 16 de Dezembro.

SHANIN Theodor

1983, «La clase incómoda»: Sociología política del campesinato en una sociedad en desarollo (Rusia 1910-1925). Tradução de Fernándo Andrade Tapia. Madrid, Alianza Editorial [«Alianza Universidad»; 369].

1980, «A definição do camponês: Conceituações e desconceituações: o Velho e o Novo em uma discussão Marxista», Estudos $C E-$ $B R A P$ (Rio de Janeiro), Vozes, n. ${ }^{0}$ 26, pp. 41-80.

SiLva Elisete Marques

2003, Impactos da ocupação colonial nas sociedades rurais do sul de Angola. Lisboa, CEA - Centro de Estudos Africanos; ISCTE - Instituto Superior de Ciências do Trabalho e da Empresa [ «Occasional Papers Series»; 8].

Recepção do manuscrito: 04/08/2015

Conclusão da revisão: 20/05/2016

Aceite para publicação: 30/05/2016

Title: Family farming in Angola: the conceptual traps of dichotomous classification.

\footnotetext{
Abstract: In the debate on the need for development of family farming in Angola has been taken for granted a set of dichotomies self - explanatory, which engenders a false transparency of its concept, and of the arguments in favour of family farming has been trying to get in the colonial past proof of success for the future economic and social development of the country. However, if on the one hand, these dichotomies sustain themselves more by a kind of syllogisms, on the other
} 
hand, the use of the colonial past neglects the story by not considering the fact that family farming in the colonial era, had at its base land dispossession of Africans, a working system forced colonial monopoly on production and trade in agricultural products to the detriment of Africans and subsistence agriculture. Against this dichotomous reasoning, the goal of this work is to contribute to an understanding of the current sense of family farming in Angola.

Keywords: Angola, family agriculture, peasantry.

\section{Garcia Neves Quitari}

É Professor Auxiliar do Departamento de Sociologia da Faculdade de Ciências Sociais da Universidade Agostinho Neto, membro participante do Agrarian Summer School, organizado pelo African Institute of Agrarian Studies, com sede em Harare, República do Zimbabwe e pesquisador filiado ao Projecto BRASSAN (Brasil e Angola: Segurança e Soberania Alimentar). É licenciado em Ciências Sociais pela Universidade Federal Fluminense (UfF) e Mestre em Sociologia e Direito pelo Programa de Pós-graduação em Ciências Jurídicas e Sociais do Instituto de Filosofia e Ciências Humanas (IFCH) da mesma universidade, na República Federativa do Brasil. É autor dos seguintes artigos publicados em Angola: "A “objectividade" do conhecimento nas Ciências Sociais: Uma leitura de Max Weber através de um sociólogo brasileiro", Mulemba - Revista Angolana de Ciências Sociais (Luanda), vol. Iv, n. ${ }^{\circ}$ 7, Maio de 2014, pp. 527-535; «O problema da terra. O Estado e a redistribuição de direitos à terra: o caso do Waku Kungo», Mulemba Revista Angolana de Ciências Sociais (Luanda), vol. I, n. ${ }^{\circ}$ 2, Outubro de 2011, pp. 29-43; «Estado Democrático de Direito: de Habermas ao "dilema" africano", Mulemba - Revista Angolana de Ciências Sociais (Luanda), vol. II, n. ${ }^{\circ}$ 3, Maio de 2012, pp. 59-74; «O problema da terra. Estado e a redistribuição do direito à terra: o caso do Waku Kungo», Contexto. Revista de Estudos Científicos e de Desenvolvimento (Luanda), n. ${ }^{\circ}$ 2, 2011, pp. 07-11.

[e-mail: garcianeves@gmail.com] 